\title{
High Prevalence of Undernutrition among Elderly People in Northwest Ethiopia: A Cross Sectional Study
}

\author{
Dawit Tessfamichael $^{1}$, Azeb Atnafu Gete ${ }^{2}$, and Molla Mesele Wassie ${ }^{2 *}$ \\ ${ }^{1}$ Amhara Regional Health Bureau, Bahir Dar, Ethiopia \\ ${ }^{2}$ Department of Human Nutrition, Institute of Public Health, University of Gondar, Gondar, Ethiopia
}

Received: July 19, 2014; Accepted: December 12, 2014; Published: December 22, 2014

*Corresponding author: Molla Mesele, Lecturer, Department of Human Nutrition, Institute of Public Health, University of Gondar, Ethiopia, E-mail:molmesele@gmail.com

\begin{abstract}
Background: Nutritional status of elderly is an important determinant of their health and quality of life. Elderly people are more vulnerable for nutritional insults as compared to adults. Undernutrition among elderly people is becoming significantly high regardless of the progress on health care system. This study was aimed to assess prevalence and associated factors of under nutrition among elderly people in Gondar town, Northwest Ethiopia.
\end{abstract}

Methods: A community based cross-sectional study was conducted. Two stage cluster sampling technique was used to select study participants. A total of 757 subjects were included in this study for nutritional status assessment. The predictive value of the variable to Undernutrition was identified by bivariate and multiple logistic regression analysis.

Results: The prevalence of undernutrition was approximately $21.9 \%$ in elderly people included in this study. Multiple analysis found that unable to read and write [AOR $2.795 \% \mathrm{CI}$ (1.7-5.2)], being female [AOR 3.0 95\% CI (1.6-5.4)], being older [AOR 38.1 95\% CI (15.0-96.9)], being poor [AOR $1.895 \% \mathrm{CI}(1.0-3.2)]$ and have poor dietary diversity score [AOR 3.7 95\% CI (1.8-7.6)] are independently and negatively associated with nutritional status of elderly people.

Conclusion and recommendation: This study indicated high prevalence of undernutrition among elderly people in Northwest Ethiopia. Old age range, gender, educational status, dietary diversity score and wealth index were found to be the factors affecting under nutrition of elderly people. Nutrition intervention and educations focusing on very old and female elderly people in improving health care and dietary practice are highly recommended in this study area.

Keywords: Undernutrition; Elderly people; Prevalence; Northwest Ethiopia

\section{Abbreviations}

ANRS: Amhara National Regional State; AOR: Adjusted Odds Ratio; BMI: Body Mass Index; BoFED: Bureau of Finance and Economic Development; DDS: Dietary Diversity Score; MUAC: Mid Upper Arm Circumference; SPSS: Statistical Package for Social Science; UHEPs: Urban Health Extension Professionals; WHO: World Health Organization

\section{Background}

Increasing number of Elderly people gives an insight to the global community to reconsider the suitability of health infrastructures for the elderly people [1]. Eleven percent of the world population and $3.2 \%$ of Ethiopian population is categorized under elderly population aged $\geq 65$ years [2].

Old age people are more susceptible for malnutrition and infection. The cost of health expenditure associated with treating the infection and/or malnutrition is also high $[3,4]$. Older people are highly neglected from different health and social interventions carried out by different stake holders [5]. Nutrient needs of older people are different due to natural aging process, dental problems and psychosocial issues. This makes them different and demands critical nutritional evaluation and follow up [6].

In Ethiopia the elderly population is growing rapidly which could increase burden of malnutrition and other non communicable diseases in the future [7]. Most studies on malnutrition in Ethiopia are focusing in children and adults. The increasing number of elderly people with less effort to combat their health and nutritional needs seek great attention in Ethiopia. However, there are no studies which assess the determinants of malnutrition in elderly people in Ethiopia.

Therefore, the aim of this study is to determine the prevalence of undernutrition and to identify risk factors associated with undernutrition in elderly people. Data obtained from this study will be useful for raising awareness of the nutrition needs of elderly people and will be a base for policy makers and planners.

\section{Methods}

\section{Study setting and design}

A community based quantitative cross-sectional study was conducted from July to October, 2013 in Gondar town which is located in northwest Ethiopia.

\section{Study population}

All old people aged $\geq 65$ years old who were living in Gondar town were the source population. 


\section{Sample size and sampling method}

The final sample size of 757 was determined by using a single population proportion formula. Two stage cluster sampling technique was used to address the study subjects. Simple random sampling technique was undertaken to select 5 kebeles (smallest administrative unit) in the town. Three ketenas' (clusters) in each kebele were also selected by simple random sampling and all elderly people found in the selected cluster were considered as study subjects.

\section{Data collection instrument}

Data were collected by using a structured questionnaire. The questionnaire was pre tested before actual data collection. Ten urban health extension professionals with 3 nurse supervisors were collected the data after 3 days of training.

Socio demographic (age range, family size and marital status) and economic characteristics (educational status of participants and partner, occupation of care taker, with whom participants are living and income status) were evaluated in our study participants. The questionnaire also contained health (illness for the last 3 months, yes/no; visit health facility, yes/no; taking medication, yes/no; most common diseases) and dietary habits questions (decline food intake yes/no; reasons for declined food intake, meal timing). Dietary Diversity Score (DDS) was considered low for respondents eaten $<3$ food items, middle when eaten 4-5 food items and high when eaten $>5$ major food items per day.

\section{Anthropometric measurements}

Height was measured using portable height meter. Participant were barefoot, legs straight, shoulders relaxed and to look straight ahead at the horizontal plane. Participants were also asked to inhale deeply, hold the breath and maintain an erect position just before taking the measurement. Reading of height measurement was taken twice to the nearest $0.1 \mathrm{~cm}$. But for those people with kyphosis and unable to measure their height, arm span was used instead $[8,9]$. The weight was measured with a portable digital weight scale. Participants were informed to wear minimum clothing and stand still in the middle of the scale's platform. Reading of weight was taken twice to the nearest $0.5 \mathrm{~kg}$. In this study nutritional status was considered as normal when Body Mass Index (BMI) was between $18.5 \mathrm{Kg} / \mathrm{m}^{2}$ to $24.9 \mathrm{Kg} / \mathrm{m}^{2}$ and undernutrition when BMI was less than $18.5 \mathrm{Kg} / \mathrm{m}^{2}$.

\section{Ethical consideration}

Ethical clearance was obtained from the Institutional Review Board (IRB) of the University of Gondar, College of medicine and health sciences, Institute of Public Health. Formal letter of cooperation was written for Gondar town Health Office. Consent of town health office and respective kebeles was also obtained. Informed consent was obtained from each study subject. Any involvement in the study was done after obtaining complete consent. All data obtained were kept confidential by using codes.

\section{Statistical analysis}

Data were entered into Epi info version 3.5.1 after cleaning and coding and transported to SPSS version 20 statistical software package for analysis. Data for categorical variables were presented in terms of their frequency. Associations between undernutrition and education status, wealth index age range, gender and dietary factors were tested using bivariate and multivariate logistic regression analysis and expressed as Odds Ratios (OR) with 95\% Confidence Intervals (CI). The level of significance was set at 0.05 .

\section{Results}

\section{Socio demographic characteristics}

Socio demographic and economic characteristics of elderly people in Gondar town were present in Table 1. A total of 757 elderly people were participated in the study. The median age of the respondent was 71.4 years. Around two third of the respondents were females. The majority of respondents

Table 1: Socio-demographic and economic characteristics of elderly people in Gondar town, 2013.

\begin{tabular}{|l|c|c|}
\hline Socio-demographic characteristics & Number (n) & Percent (\%) \\
\hline Age group in years & & \\
\hline $65-74$ & 554 & 73.2 \\
\hline $75-84$ & 163 & 21.5 \\
\hline$\geq 85$ & 40 & 5.3 \\
\hline Family size & & \\
\hline$<4$ & 485 & 64.2 \\
\hline$\geq 4$ & 272 & 35.8 \\
\hline Marital status & & \\
\hline Widowed & 467 & 61.7 \\
\hline Married & 236 & 31.2 \\
\hline Single/Divorced/separate & 54 & 7.1 \\
\hline Educational status of respondents & & \\
\hline Unable to read and write & 440 & 58 \\
\hline Read and write & 244 & 32.2 \\
\hline Primary education & 51 & 6.7 \\
\hline Secondary and above & 22 & 2.9 \\
\hline Educational status of partner (n=236) & & \\
\hline Unable to read and write & 132 & 56 \\
\hline Read and write & 69 & 29.2 \\
\hline Primary education & 23 & 9.3 \\
\hline Secondary \& above & 13 & 5.5 \\
\hline Occupation of care taker (n=272) & & \\
\hline Government employee & 122 & 44.8 \\
\hline Farmer & 3 & 14.3 \\
\hline Merchant & 108 & 39.7 \\
\hline Others & 39 & 1.1 \\
\hline With whom respondents are living & & \\
\hline With partner & 236 & 31.2 \\
\hline With children & 646.9 \\
\hline Alone & 13 & 1.7 \\
\hline Others & & \\
\hline Wealth index & & 38.8 \\
\hline Poor & & 28.8 \\
\hline Middle income & & \\
\hline Rich & & \\
\hline & & \\
\hline & & \\
\hline
\end{tabular}


(73.4\%) were orthodox Christians in religion. Regarding marital status $61.7 \%$ were widowed and $31.2 \%$ were married. A higher proportion of respondents (58\%) cannot read and write. The wealth index result showed that $38.8 \%$ of respondents were poor. The mean family size of respondents was 4.05 .

\section{Health status of elderly}

Regarding to the health status of respondents, 285 (37.6\%) were sick in the last three months. From those who were sick, $67 \%$ of elderly were taking medication at the time of data collection. The most commonly mentioned diseases for taking medication were joint pain (29\%), hypertension $(25.3 \%)$, and diabetic mellitus (13.7\%). From the total respondents, 163 (21.5\%) of elderly have been suffering from decline of food intake. Digestive system problem and chewing problem are being the main reason for loss of appetite (Table 2).

\section{Dietary Diversity of elderly}

The dietary diversity score was low, middle and high for 51 (6.6\%), 273 (36.1\%) and 433 (57.2\%) elderly respectively. The median dietary diversity score was 2 . The mean meal frequency of respondent was 2.9 ( $\mathrm{SD} \pm 0.47$ ). The meal time was irregular for $566(74.8 \%)$ of respondents. Two third of elderly were fed themselves without any difficulty and 234 (30.9\%) fed with difficulty. Loss of appetite was reported in $21.5 \%$ of respondents (Table 2).

\section{Factors associated with undernutrition}

Age, sex, wealth index, dietary diversity score, sometimes feeding with family members and sometimes alone, feeding ability, time of fasting, being sick for the last 3 months, taking medication and functional mobility had shown a significant association with undernutrition in the bivariate analysis. These variables were taken to the multivariate analysis to saw their independent contribution (Table 3).

Age is found to be associated with undernutrition in elderly people. Oldest old and middle old were more likely to be undernourished than young old people [AOR $38.195 \%$ CI (15.0-96.9)]. Females were three times more likely to be undernourished as compared to males [AOR 3.0 95\% CI (1.65.4)]. Elderly people who cannot read and write were 2.7 times more likely to be undernourished [AOR 2.7 95\% CI (1.7- 5.2)]. The risk in low income elderly to be undernourished was 1.8 higher than in rich elderly [AOR 1.8 95\% CI (1.0-3.2)]. With regard to wealth index, middle income elderly were 2.5 times more likely to be undernourished as compared to rich [AOR $2.595 \%$ CI (1.4-4.7)]. Dietary diversity score is found to be significantly and positively associated with under nutrition. According to this study, elderly people with poor DDS were 3.7 times more likely to be undernourished when compared to those with high DDS[AOR 3.7 95\% CI (1.8-7.6)] (Table 3).

\section{Discussion}

In our study the prevalence of undernutrition among elderly people was $21.9 \%$. This finding is higher when compared with studies in Razavi khorasan and Iran [10-12] but low when
Table 2: Characteristics of respondents with respect to factors associated with undernutrition of elderly people, 2013.

\begin{tabular}{|c|c|c|}
\hline Variable & Number (n) & $\begin{array}{l}\text { Percent } \\
(\%)\end{array}$ \\
\hline \multicolumn{3}{|l|}{ Illness for the last 3 months } \\
\hline Yes & 285 & 37.6 \\
\hline No & 472 & 62.4 \\
\hline \multicolumn{3}{|l|}{ Visit health facility $(n=285)$} \\
\hline Yes & 199 & 70 \\
\hline No & 86 & 30 \\
\hline \multicolumn{3}{|l|}{ Taking medication $(n=285)$} \\
\hline Yes & 191 & 67 \\
\hline No & 94 & 33 \\
\hline \multicolumn{3}{|c|}{$\begin{array}{l}\text { Most common diseases mentioned } \\
(\mathrm{n}=285)\end{array}$} \\
\hline Joint pain & 83 & 29 \\
\hline Hypertension & 72 & 25.3 \\
\hline Diabetic mellitus & 39 & 13.7 \\
\hline Hearing problem & 31 & 10.9 \\
\hline Indigestion problem & 27 & 9.5 \\
\hline Visual problem & 24 & 8.4 \\
\hline I don't know & 9 & 3.1 \\
\hline \multicolumn{3}{|l|}{ Decline food intake } \\
\hline Yes & 163 & 21.5 \\
\hline No & 594 & 78.5 \\
\hline \multicolumn{3}{|c|}{$\begin{array}{l}\text { Reasons for declined food intake } \\
(n=163)\end{array}$} \\
\hline Digestive system problem & 74 & 45.4 \\
\hline Loss of appetite & 35 & 21.4 \\
\hline Chewing problem & 39 & 23.9 \\
\hline Swallowing problem & 15 & 9.2 \\
\hline \multicolumn{3}{|l|}{ Dietary diversity score } \\
\hline Low & 51 & 6.6 \\
\hline Middle & 273 & 36.1 \\
\hline High & 433 & 57.2 \\
\hline \multicolumn{3}{|l|}{ Meal timing } \\
\hline Regular & 566 & 74.8 \\
\hline Irregular & 191 & 25.2 \\
\hline
\end{tabular}

compared to study done in lake Victoria basins of Kenya, Uganda and Tanzania [13]. This difference may be due to variation in geographic setting and socioeconomic status of the study population. The prevalence of undernutrition was higher in females $(18.6 \%)$ than males (3.3\%). Prevalence of under nutrition in those middle old age groups was (55.2\%) and 75\% in oldest old age groups.

Age, sex, educational status, wealth index and dietary diversity score of respondents found to be associated with undernutrition in elderly people. Females were three times more likely to be undernourished as compared to males. This finding is similar with the study done in Malaysia [14] but contradicts with study done in Kenya [13]. This could be due to the fact that female elderly still remain the care takers of the young children but given low care needed to themselves. Females are also exposed to many comorbid illnesses with no pension paid as compared to male elderly. 
Table 3: Factors associated with undernutrition in elderly people aged $\geq 65$ years, Gondar Town, 2013.

\begin{tabular}{|c|c|c|c|c|}
\hline \multirow{2}{*}{ Variables } & \multicolumn{2}{|c|}{ Undernutrition(n) } & \multirow{2}{*}{$\operatorname{COR}(95 \% \mathrm{CI})$} & \multirow{2}{*}{${ }^{\#}$ AOR(95\%CI) } \\
\hline & Yes & No & & \\
\hline \multicolumn{5}{|c|}{ Education status of respondents } \\
\hline Able to Read \& write & 58 & 259 & 1 & 1 \\
\hline \multicolumn{5}{|l|}{ Wealth index } \\
\hline Medium & 52 & 166 & $1.6(1.0-2.5)$ & $2.5(1.4-4.7)$ \\
\hline Rich & 41 & 204 & 1 & 1 \\
\hline \multicolumn{5}{|l|}{ Sex } \\
\hline Female & 141 & 422 & $2.3(1.4-3.6)$ & $3.0(1.6-5.4)$ \\
\hline Male & 25 & 169 & 1 & 1 \\
\hline $65-74$ & 30 & 10 & $33.1(15.2-71.3)$ & $38.1(15.0-96.9)$ \\
\hline $75-84$ & 90 & 73 & $13.4(8.7-20.2)$ & $14.6(8.9-24.0)$ \\
\hline$\geq 85$ & 46 & 508 & 1 & 1 \\
\hline \multicolumn{5}{|l|}{ Dietary diversity score } \\
\hline Low DDS & 23 & 27 & $3.7(2.0-6.7)$ & $3.7(1.8-7.6)$ \\
\hline Middle DDS & 61 & 212 & $1.2(0.9-1.8)$ & $1.1(0.7-1.8)$ \\
\hline High DDS & 82 & 351 & 1 & 1 \\
\hline
\end{tabular}

\#adjusted for sex, educational status, wealth index and Dietary Diversity Score (DDS)

Age is found to be associated with undernutrition in elderly people. Oldest old and middle old were more likely to be undernourished than young old people. This finding was similar with a study done in Malaysia and United Kingdom [14,15]. This might be due to the natural ageing process of elderly and the subsequent chronic and acute illnesses with poor outcome occurred in elderly as their age increases.

Educational status was also one of the factors which had showed significant association with undernutrition. Elderly people who cannot read and write were 2.7 times more likely to be undernourished. This finding is comparable with studies done in Iran and Kenya $[10,16]$. This might be due to educated people have good feeding practice and have better life style.

With regard to wealth index, middle income elderly were 2.5 times more likely to be undernourished as compared to rich. Low income subjects were also 1.8 times more likely to be undernourished than rich. This result is supported by the study done in Russia which states wealthiest individuals have high BMI as compared to poor individuals and at the same time poor elderly are more likely to be undernourished as compared to wealthier [17]. This might be due to wealthiest individuals have enough food to eat and have relatively better life style as compared to poor who are always in trouble to secure their daily food intake.

Dietary diversity score is found to be significantly and positively associated with under nutrition. According to this study, elderly people with poor DDS were 3.7 times more likely to be undernourished when compared to those with high DDS. This result is the same as the study done in Dadab refugee camp in
Kenya [16]. This might be due to low calories and protein content of less diversified foods as compared to high diversified foods.

\section{Limitation of the Study}

The study focused only on the urban population and might not represent the rural dwellers. Also, dietary assessment methods and indicators for micronutrient status did not assess of the respondents.

\section{Conclusions and Recommendation}

This study showed that the prevalence of undernutrition among elderly people is high in Northwest Ethiopia. Being female, have a very old age, being poor and have low dietary diversity score are the risk factors for undernutrition of elderly people. Nutritional support to improve the dietary diversity score of old age people especially female elderly is highly recommended in this study area.

\section{Acknowledgements}

Authors would like to thank University of Gondar for approval of ethical clearance. Our heartfelt thanks go to study participants who spent their precious time in responding to our questionnaire. All data collectors and the supervisors are highly acknowledged for the utmost effort they put to the quality of this research. Authors declare that there is no conflict of interest.

\section{Authors' contribution}

Molla Mesele was the corresponding author. Dawit Tessfamichael made substantial contributions in conception and 
design, acquisition of data, analysis and interpretation of data. Azeb Atnafu Participated in the design of the study and in the statistical analysis. Molla Mesele Participated in the design of the study, writing of results and discussion and has been drafting the manuscript. All authors read and approved the final manuscript. Dawit Tesfamichael wrote the paper.

\section{References}

1. WHO. World Health Day 2015: Food safety. Available from: http:// www.who.int/campaigns/world-health-day/2015/event/en/

2. Charles T, Assefa H, Tesfayi G, Hassan A. Population Dynamics, Food/Nutrition Security and Health in Ethiopia: Delicate Balance of Vulnerability \& Resilience. IUSSP Marrakech; 30 Sept 2009: Poster Session \#3.

3. Barker LA, Gout BS, Crowe TC. Hospital Malnutrition: Prevalence, Identification and Impact on Patients and the Healthcare System. Int J Environ Res Public Health. 2011; 8(2): 514-27. doi: 10.3390/ ijerph8020514

4. Hrnciarikova D, Juraskova B, Zadak Z, Hronek M. Present state of evaluating malnutrition in the elderly- analysing indicators. Biomed. Pap Med .Fac Univ Palacky Olomouc Czech Repub. 2006; 150(2):21721.

5. Beales S. Why investing in reducing age based vulnerabilities is necessary in the global economic crisis. 2009.

6. Nestle Nutrition. Malnutrition in the Older Adult. 2010. Available from: http://www.nestle.com/asset-library/documents/ library/events/2010-malnutrition-in-older-people/factsheet malnutrition_e_for-web.pdf

7. United Nations: Population Division DESA. 2012

8. Mohanty SP, Babu SS, Nair NS. The use of arm span as a predictor of height: A study of south Indian women. J Orthop Surg (Hong Kong). 2001; 9(1): 19-23.

9. Ashutosh N. Aggarwal, Dheeraj G, Jindal SK. Interpreting spirometric data: Impact of substitution of arm span for standing height in adults from north India. Chest. 1999;115(2): 557-62.

10. N Mokhber, MR Majdi, M Ali-Abadi, MT Shakeri, M Kimiagar, R Salek, et al. Association between Malnutrition and Depression in Elderly People in Razavi Khorasan. Iran J Public Health. 2011; 40(2): 67-74.

11. Kaiser M, Bauer J, Rämsch C, Uther W, Guigoz Y, Cederholm T, et al. Frequency of malnutrition in older adults: A multi national perspective using the mini nutritional assessment. J Am Geriatr Soc. 2010; 58(9):1734-8. doi: 10.1111/j.1532-5415.2010.03016.x.

12. Aliabadi M, Kimiagar M, Ghayour-Mobarhan M, Shakeri MT, Nematy $M$, et al. Prevalence of malnutrition in free living elderly in Iran: a cross sectional study. Asia Pac J Clin Nutr. 2008;17(2):285-9.

13. MJ Cheserek, PJ Tuitoek, JN Waudo, JM Msuya, JK Kikafunda. Anthropometric characterstics and nutritional statusof older adults in the lake victoria basin of east Africa: region, sex and age differences. African Journal Clinical Nutrition. 2012.

14.Seong Ting Chen, Hooi Jiun Ngoh, Sakinah Harith. Prevalence of Malnutrition among Institutionalized Elderly People in Northern Peninsular Malaysia: Gender, Ethnicity and Age-specific.2012; 141148.

15. Forster S, Gariballa S. Age as a determinant of nutritional status: A cross sectional study. Nutr J. 2005; 4: 28. doi: 10.1186/1475-2891$4-28$.

16. Help Age International. Nutrition and baseline survey of older people in three refugee camps in Dadaab.2011.

17. Jensen TR .socioeconomic status, nutrition and health among elderly. In: Perspectives on the Economics of Aging. 2004. 